\title{
John Ambrose Fleming and the Beginning of Electronics
}

\author{
H. F. Dylla and Steven T. Corneliussen \\ Thomas Jefferson National Accelerator Facility (Jefferson Lab) \\ 12000 Jefferson Avenue \\ Newport News, VA 23606
}

2004 was the centenary of John Ambrose Fleming's momentous patent on the thermionic diode that can be called the birth of electronics. The "Edison effect" was discovered in 1882; this was later shown to be the result of thermionic emission of electrons from a heated filament into a vacuum. Edison did not make any significant devices based on this discovery, and the effect was ignored for more than 8 years. In 1890 Fleming explained the effect and showed that the thermionic diode could be used as a rectifier. Fourteen years later Fleming filed his 1904 patent on the thermionic diode. It was the first public announcement of the electron tube; this revolutionized the development of radio and led to the invention of the thermionic triode by Lee de Forest in 1906. The background to these events will be described.

\section{Introduction}

In a November 1904 note to Guglielmo Marconi, the inventor of radio, the British electrical engineer Prof. John Ambrose Fleming (1849-1945) wrote that he had "found a method of rectifying electrical oscillations," adding that he had not "mentioned this to anyone yet, as it may become very useful." (See Figures 1 and 2.) Indeed the thermionic vacuum diode did become very useful — so much so that Fleming's phrasing calls to mind the famous understatement of James Watson and Francis Crick in Nature a half-century later. "It has not escaped our notice," they wrote about their discovery of the DNA double helix, "that the specific pairing we have postulated immediately suggests a possible copying mechanism for the genetic material." Just as the double helix inaugurated the age of molecular biology, Fleming's vacuum tube inaugurated the age of electronics - and dominated it until the advent of the transistor. Both the double helix and the vacuum tube merit the term revolutionary, but whereas knowledge about DNA came mainly from the steady advance of pure scientific understanding, the vacuum tube initially resulted mainly from the uneven advance of practical technology, gradually informed by growing scientific understanding.

*Dylla@JLab.org 
On the 16th of that November, Fleming applied for a patent on "Improvements in detecting and measuring alternating electric currents.” The patent was granted in 1905. ${ }^{2}$ According to historian of electronic communications George Shiers, writing in Scientific American, Fleming's device "looked like a dimly glowing incandescent lamp in which a flat metal plate was supported between the legs of a carbon filament in the form of a single loop." By analogy to a one-way water valve, Fleming called it the oscillation valve, but in his 1906 book The Principles of Electric Wave Telegraphy, he referred to it as a kind of "vacuum tube cymoscope," which according to Shiers was "a generic name that he introduced with his invention of the cymometer, an instrument for measuring the length of electric waves." ${ }^{.4}$ Fleming's vacuum tube has been called by many other names as well: the two-electrode radio rectifier, the glow lamp detector, the vacuum diode, the kenotron, the thermionic valve, the thermionic tube, the thermionic vacuum diode, the Fleming valve. Paul Redhead has called it the Edison-Fleming diode, ${ }^{5}$ because it reaches back two decades to the Edison effect, named for Thomas Alva Edison.

By the 1920s, the technological revolution begun by the vacuum tube was well underway. In 1923, an address by Fleming himself - heard, fittingly, via the "wireless valve receivers" of the new communications technology of radio ${ }^{6}$ - retrospectively narrated how the valve came into being. Excerpts from that talk, beginning with the following, can be used to structure the story of Fleming and the beginning of electronics: "As the earliest stages in the invention of the wireless valve were made by me at University College, London, between 1889 and 1904, it may interest some of those who are now listening to these remarks of mine by means of valve receivers, to have some short account of the beginnings of that invention."

\section{Fleming's Background}

To outline how Fleming came to be at University College and came to focus on the new technology of radio is, in part, to begin to see how he came to contribute his valve to technoscientific history. It is said that by the age of thirteen, Fleming "showed early signs of prodigy and delivered his first lecture on electromagnetic phenomena." "According to his colleague and biographer J. T. MacGregor-Morris, Fleming at age 24 was influenced in 1873 by studies of "how hot bodies lose electrical charges," studies in which it was shown that "the hotter the body the more rapidly did it lose a charge of electricity, and also that when an iron ball was 
at a bright red heat and well insulated it could be charged with negative electricity, but could not for an instant retain a positive charge." MacGregor-Morris says this was "the embryo of the idea underlying the action of the wireless valve, but the world had to wait some thirty years before this experimental result was applied to the wireless field by Fleming." 8 Fleming presented his first professional paper in 1874 - "On the new contact theory of the galvanic cell”- and continued publishing for another two-thirds of a century, until age 92 in 1941. At age 28, he was studying at Cambridge and conducting research under James Clerk Maxwell. In the early 1880s, he became a consultant to the Edison Electric Light Company of London. In 1885, University College invited him to become a professor and to establish a department of electrical engineering. He accepted, and stayed in the position for over forty years, lecturing and researching a variety of electrical and electronics engineering questions. His many technical and scientific contributions include the famous rules that students learn for visualizing and remembering the directional relationships among the magnetic field, the current, and a dynamo (the right-hand rule) or a motor (the left-hand rule).

Fleming maintained strong links to industry from his position in academia. In 1899 he began three decades as a scientific adviser to the Marconi Company. MacGregor-Morris says that Fleming specified "the power plant necessary to produce the powerful electrical oscillations deemed essential if Marconi's project of the transmission across the Atlantic and the reception of such signals were to be realized." MacGregor-Morris continued: "The scale of the transmitting plant would have to be gigantic in comparison with the puny 10-inch spark coils and Leyden jars, working with a few cells. A 25-horse-power oil engine was specified by Fleming to drive an alternator" at the transmission site in Cornwall. On December 12, 1901, Marconi and two assistants were in Newfoundland, where "they heard in earphones, faintly but distinctly, the prearranged signals." These signals, three sets of three dots each, were "the letter $\mathrm{S}$ in the Morse code, which were being transmitted from Cornwall round one-eighth of the globe."9 (See Figure 3.)

So Fleming operated in both the academic-scientific and technological-commercial worlds. As a combination researcher, professor, engineer, and consultant, he is an early example of the kind of fruitful collaboration between those worlds that we are still learning how to nurture and enhance. 
For illuminating that present-day effort, the story of the advent of Fleming's oscillation valve, and of the beginning of electronics itself, might offer some special light.

\section{The Edison Effect-and the Effect of Edison}

Fleming's 1923 radio address continued by mentioning Edison and by beginning to describe the practical problem that led eventually to Fleming's "oscillation valve": "In 1882 the electric incandescent lamp, so familiar to us all, was perfected by Edison and Swan. The first lamp consisted of a carbon filament or thread enclosed in a glass bulb from which all the air was pumped out. When an electric current was sent through the thread it glowed with a brilliant light. It was soon found that the bulb became blackened on the inside as the valve was used, and the filament or thread was after a certain time burnt through at some place by excessive heating."

That blackening, discussed in detail below, hints at the phenomena on which the birth of electronics was based, but if Fleming were delivering his retrospective radio address today, he might divert momentarily at this point to discuss what can now be seen more clearly about the dynamics of technoscientific advance during the era when electronics was born. A good overview of that dynamics is to be found in a new kind of college textbook that came out in 2003: Inventing America: A History of the United States. Its co-authors - prominent historians including historian of physics Daniel J. Kevles - have sought to create "a new history of the United States whose unifying theme is innovation." In other words, rather than treat technoscience in the usual way, as a huge external but mainly unexamined force whose effects drive much of history, they expand historical understanding to integrate technoscience fundamentally. Inventing America says that the technological advances of the late nineteenth century, though often still the province of nonscientific tinkerers and semiscientific inventors, "were based more in science than those of earlier periods," and that the era's scientific advances "launched new waves of scientific research in the United States" because of the possibilities for practical applications. For example, "the ability to manipulate electrons" that stemmed from J. J. Thomson's 1897 discovery in England of the electron itself "made it possible to amplify electrical signals, facilitating long-distance telephone calls and the transmission of radio signals." 10 
Deep scientific understanding did of course eventually animate the electronics industry, and in fact signal amplification and transmission followed rectification in short order-though not necessarily because of deep scientific understanding — as additional revolutionizing capabilities of Fleming's 1904 oscillation valve. But unlike the pure-science context for the mid-1950s discovery of DNA, the context for the beginning of electronics was the uneven advance of practical technology, albeit gradually informed by some degree of growing scientific understanding. Much about the controlling technological context was defined by Edison, and by electricity itself, which Inventing America calls "the hallmark technology of the era, widely regarded as mysterious and all powerful, capable of transforming every facet of American life," just as it calls Edison the era's "most celebrated independent inventor." 11

From America, the practical-minded, commerce-focused Edison even defined much about the context in which Fleming worked in England. October 2004 marked the 125th anniversary of Edison's incandescent light bulb, invented in 1879 after some 3000 experiments. By 1882-the year when, as Fleming told his radio audience, "the electric incandescent lamp so familiar to us all was perfected"-Edison had exerted enormous effort on a number of technical, commercial and even political fronts to establish the Pearl Street power station for serving part of Manhattan. Not only did he cause vacuum bulbs to be produced in quantity, but he developed steam-based power generation, power distribution, and electrical apparatus ranging from switches to fuses. The financier J. P. Morgan became a backer of Edison's ventures, which evolved and merged with other ventures to become the General Electric Company. According to Inventing America, Edison "symbolized the era's marriage of creativity to economic incentive," and as his technicalcommercial ventures expanded, he created at Menlo Park and elsewhere "a model of collaborative research, a way of institutionalizing the process of technological advance." By 1900, GE had founded America's first formal industrial laboratory. By 1902, only two decades after Pearl Street, the United States had some 2250 power stations, and both GE and Westinghouse were manufacturing electrical products. ${ }^{12}$

But the effect of Edison's innovative energy was certainly not to transform the overall scientific spirit into the kind of academic one in which Watson and Crick operated in biology during the $1950 \mathrm{~s}$ — or, for that matter, in which many electronics, photonics, and quantum electronics 
researchers operate now. It was something in between pure practicality and pure science. In fact, one effect of Edison was to accentuate, in America, the markedly practical-minded spirit that had existed concerning technoscience since the time when Benjamin Franklin founded, and Thomas Jefferson later led, the American Philosophical Society. That organization was devoted to "all philosophical Experiments that let Light into the Nature of Things, tend to increase the Power of Man over Matter, and multiply the Conveniencies or Pleasures of Life." Edison cared less about letting light into the nature of things, and more about increasing the power of man over matter so as to multiply "conveniencies." Redhead quotes something Edison wrote in 1884 that illustrates the hyper-busy inventor's disdain for the ivory-tower view of physical research: "I never have time to go into the esthetic part of my work ... . But it has, I am told, a very important bearing on some law now being formulated by the Bulged-headed fraternity of the Savanic World."13

In England, Fleming nevertheless operated in a different fashion from Edison, with some degree of "bulged-headedness" as a technoscientific savant. Fleming did take time to think about physical questions that didn't seem obviously to bear on whichever commercial-technological prospects seemed most worth grasping for at a given moment. It is sometimes said that the birth of electronics could actually have come many years earlier than 1904, if only more researchers and technologists had looked harder for ways to make connections among existing and emerging ideas. Shiers, for example, suggests that based on what was known in the $1880 \mathrm{~s}$, "a practical system of wireless telegraphy utilizing an electron tube could have been demonstrated four years before Heinrich Hertz proved the existence of electromagnetic waves." ${ }^{14}$ And MacGregorMorris writes, "Having arrived at [a] mental picture of the action of the one-way passage of electricity across a vacuous space by 1896 it may be surprising to some that a period of eight years should elapse ere the thought occurred to Fleming to apply the effect in the field of radiotelegraphy." MacGregor-Morris continues, however, by offering an explanation that calls to mind the way Thomas Edison operated: "In answer to this criticism it may be noted that at this period Fleming was carrying a load at least enough for two men of good mental stature, and it was quite impossible to take on further work." 15

Nevertheless Fleming did try to find time to investigate deeply. His 1923 radio address continued: "In the course of my experience as scientific advisor of the Edison Electric Light 
Company, I noticed that in some lamps there was a clear line on the glass bulb on which no blackening took place, which indicated that the carbon particles had been shot off from the overheated point in the filament in straight lines. The undamaged half of the hairpin-shaped filament by intercepting this shower of carbon atoms caused a sort of shadow or line of no black deposit to be produced on the inner surface of the bulb. A little later on I found that these particles thus shot off were all electrified with so-called negative electricity, that is the kind of electricity produced by rubbing a stick of sealing wax with a bit of flannel."

Edison had first observed this blackening in 1880, and returned to it in 1882 when he introduced a second wire into his lamp and saw that a current flowed when the second electrode was positive, but that no current flowed when it was negative. The general puzzlement about these phenomena can be seen in the paper about them that Edwin J. Houston presented at the International Electrical Exhibition in Philadelphia in 1884. "Notes on phenomena in incandescent lamps" was the first publication in Transactions of the American Institute of Electrical Engineers, an organization that later merged with the Institute of Radio Engineers to become IEEE, the modern Institute of Electrical and Electronics Engineers. ${ }^{16}$ Houston considered his "notes" too modest for designation as a professional paper. "I have not prepared a paper," Houston began, "but merely wish to call your attention to a matter which, I suppose, you have all seen and puzzled over. Indeed, I wish to bring it before the society for the purpose of having you puzzle over it. I refer to the peculiar high vacuum phenomena observed by $\mathrm{Mr}$. Edison in some of his incandescent lamps." The paper goes on to wonder, "The question is, what is the origin of this current? How is it produced? Since we have within the globe a nearly perfect vacuum, we cannot conceive the current as flowing across the vacuous space, as this is not in accordance with our preconceived ideas connected with high vacua." Houston's "notes" acknowledge that he had "no theory to propound as to the origin of these phenomena," though it "may be electricity flowing through empty space, which I don't think probable.",17

Fleming's radio narrative looked back on the scientific puzzlement this way: "At that time it seemed that these charged particles were atoms of carbon, but we did not know then that chemical atoms are built up of still smaller particles called electrons. It used to be thought that atoms were not capable of being divided. The very word atom comes from two Greek works 
signifying not able to be cut up. The great discovery was, however, made about 1898 or 1899, by Sir Joseph Thomson, the present Master of Trinity College, Cambridge, that chemical atoms of matter are built up of still smaller atoms of electricity called electrons, and it was soon found that the incandescent filament of an electric lamp is sending out vast numbers of these little electrons." Nowadays, of course, we date Thomson's discovery to 1897, and he's usually called "J. J.," not "Joseph." And nowadays we recognize those "vast numbers of ... little electrons" as thermionic emission.

But that was not understood when William Henry Preece, chief electrician for the British post office, took some Edison bulbs back to England from the 1884 Philadelphia meeting and began conducting experiments. In a paper presented at the Royal Society of London in early 1885, Preece became the first to use the term Edison effect. ${ }^{18}$ By then, based on an observed relation between current and filament temperature in a bulb displaying the puzzling phenomena, Edison was able to patent ${ }^{19}$ a lamp device as a voltage indicator. Shiers says it was "the first patent in electronics," albeit with no commercial value. It has also been called "the first application of thermionic current to a useful purpose" and "the first electronic circuit, with the first thermionic tube. ${ }^{20}$

Nevertheless it is Fleming who is credited, as Shiers says, for "many careful experiments extending over two decades" that earned him "the right to be regarded as the inventor of the original electron tube." Fleming published relevant papers in 1883 and 1885, and then in 1889 resumed study of the Edison effect. Redhead says that the "first sign of the thermionic diode as an electronic device" appeared in an 1890 paper where Fleming noted - in what MacGregorMorris calls a "pregnant statement" - that when "the lamp is actuated by an alternating current, a continuous current is found flowing through a galvanometer connected between the insulated plate and either terminal of the lamp." Redhead calls this "the first observation of rectification in a thermionic diode." Still later, in an 1896 paper called "A further examination of the Edison effect in glow lamps," Fleming reported on nearly thirty more experiments. According to Shiers, if 'the word 'electron' is substituted for 'negatively charged molecules,' [this] paper is a familiar description of the elements of thermionic emission, but of course [Fleming] was ahead of his time. ${ }^{21}$ 


\section{Eureka Moment}

So by 1896 , Fleming had arrived at that "mental picture of the action of the one-way passage of electricity across a vacuous space," and that "period of eight years [would now] elapse ere the thought occurred to Fleming to apply the effect in the field of radio-telegraphy." Advancing technological understanding and partial scientific understanding would not lead to the birth of electronics until practical, commercial circumstances combined to stimulate Fleming's technoscientific imagination. The 1923 radio retrospective continued: "The next step of invention was made in 1904, when I placed around the filament of an electric lamp a cylinder of metal sealed inside the bulb, and found that a current of negative electricity could be sent from the filament to the cylinder but not in the opposite direction. This at once gave us a means for converting the feeble but rapid to-and-fro motions of electricity in an aerial wire, which are set up when electric waves from a distant transmitting station strike the aerial wires, into a current of electricity all in the same direction by including in the circuit such a lamp with a cylinder round the filament. I therefore called the instrument a valve because it acts, as regards electricity, as a valve in a pump acts for air or water. It is now called a thermionic valve."

In that passage Fleming reveals nothing about the classic Eureka moment that he described elsewhere. It was the instant when, with "a sudden very happy thought," he saw how to solve the technological — that is, not immediately scientific_- problem of radio signal rectification. However, his colleague and biographer MacGregor-Morris does quote him on that moment: "The problem before me then was to discover how to change this feeble electric oscillation into a feeble direct current which could work the ordinary cable recording instruments. There were known devices for rectifying, as it is called, low-frequency alternating currents, but nothing then known which would do it for rapid electric oscillations. Thinking over the subject intensely, I had in October, 1904, a sudden very happy thought. I recalled to mind my experiments on the 'Edison effect,' and in particular my observation that the space between an incandescent carbon filament and a cold metal plate in a bulb exhausted of its air had a one-way conductivity for electricity. Then I said to myself, 'If that is the case we have here the exact implement required to rectify high-frequency oscillations.' I asked my assistant, Mr. G. B. Dyke, to put up the arrangements for creating feeble high-frequency currents in a circuit, and I took out of a 
cupboard one of my old experimental bulbs." Fleming said his new device "acted like a valve in a pipe, which lets water or air only move in it one way. Accordingly I called this instrument a valve." 22 Shiers says the lamp taken from that cupboard was an 1889 model, "virtually the same as Edison's lamp of 1883." Another, similar lamp figured in Fleming's provisional patent application of November 16, 1904, which referred to the use of a galvanometer and a twoelement lamp for receiving radio signals. Shiers calls that lamp "the first vacuum tube in an electronic circuit.. ${ }^{23}$ (See Figures 4, 5, and 6.)

Obviously, Fleming's patent application eventually led to the innumerable consequences that in turn created centennial interest in this story, but one of the immediate results was a scientific paper, "On the conversion of electric oscillations into continuous currents by means of a vacuum valve," which Fleming presented to the Royal Society on February 9, 1905, and published in March. The terms Fleming used during this time might tell a lot about his awareness of the scientific knowledge that was then emerging. Shiers makes several observations ${ }^{24}$ about Fleming's phrasing and word choices. In the 1905 Royal Society paper, Fleming used the terms electron and free electrons in describing conduction, but in the 1904 patent application used the phrase negative electricity. Earlier, in 1902, the Royal Institution had published a Fleming article called "The electronic theory of electricity," which was reprinted in Popular Science Monthly. Shiers declares that this paper marked the first popular use of the word electron to name minute negative charges or particles. But later, in the 1906 book mentioned earlier, The Principles of Electric Wave Telegraphy, Fleming did not use the word electron in describing the current flow, reverting instead to negative electricity. In that book he also left unmentioned the theory of thermionic emission, which had been published in 1901 by O. W. Richardson, and which won for Richardson the 1928 Nobel Prize in Physics.

\section{Lee De Forest, Tinkerer}

Whatever the connection in Fleming's mind between scientific understanding and successful technology, Fleming in 1905 was about to encounter competition in the infancy of electronics from Lee De Forest, who had a Yale Ph.D. in physics, but who invented his "audion" (Figure 7) - an improved Fleming valve - by working merely as a tinkering, cut-and-try inventor. Fleming told it this way in his 1923 radio address: "Subsequently to my invention of the two- 
electrode valve, De Forest, in America, introduced the grid or spiral of wire placed between the filament and the metal cylinder, which converted it into a so-called three-electrode valve. This enabled the valve to amplify electric oscillations as well as rectify or detect them. In its most recent types, which are the outcome of the work of many able inventors, the valve can perform three duties - it can detect electric vibrations, amplify or magnify them, and also create them, and it can truthfully be described as the master weapon of the radio engineer."

Signal amplification and transmission did follow rectification as additional revolutionizing capabilities of Fleming's 1904 oscillation valve, and by the time Fleming reminisced, many able inventors had indeed made the valve the radio engineer's "master weapon." The most prominent was De Forest, said by electronics historian Robert A. Chipman to have "invented the threeelectrode vacuum tube without understanding how it worked." According to Chipman, De Forest's "grid-triode was no great success as a detector," though "it did eventually make modern radio and electronics possible." In fact, Chipman wrote, "as a detector, amplifier, and oscillator it became the foundation of modern radio, and with its derivatives it dominated electronic technology for 50 years." 25

This technological development was obviously also a commercial one, and De Forest wanted riches and fame. At different times in his life, he cited Nikola Tesla, Marconi, and Edison as his models, and like those other entrepreneurial inventors, he devoted much of his attention not just to technology but to patent law. Having done his Ph.D. dissertation on electromagnetic waves in transmission lines, he had scientific training relevant for the accomplishment that made him famous: inventing a better radio receiver. By 1905, when Fleming's valve patent was granted, De Forest was already an experienced inventor-entrepreneur, though not yet a successful one. He focused on radio, and recognized that in order to compete with Marconi, he would have to devise a system not infringing Marconi's patents-which included the one for the valve invented by Marconi's consultant Fleming. The heart of the problem appeared to be radio signal detection. De Forest tested various "triode" configurations and settled on the $o e^{26}$ for which he is now remembered. He always maintained that his invention did not stem from knowledge of the Fleming valve, but instead grew out of work he had done involving incandescent electrodes in heated gases — even though he had not mentioned anything relevant from that work when 
originally reporting it. He also claimed a distinction based on his device's involvement of a battery. Chipman calls De Forest's pair of claims "technically unjustifiable" and adds that "taken literally, they would be evidence of a scientific naïveté remarkable in an active inventor only seven years away from a Ph.D. in physics. It is more charitable to assume that the claims and their supporting narrative were developed as defenses against a potential suit for infringement of the Fleming patent." And indeed several years later a lawsuit did end in favor of Marconi, the patent's owner. Chipman says further that De Forest's "staunch loyalty to the mystical idea of a 'sensitive gaseous conducting medium' kept him from appreciating the fundamental electronic basis of the thermionic diode and triode until long after it was generally accepted."27

Among the deficient radio-signal receiving devices in use during that era, Marconi's was the coherer, which Shiers calls "an erratic device" that was "a metal tube filled with iron filings." 28 Chipman notes that although De Forest was the only participant in the creation of the initial triode, a radio detector not notably better than the coherer, it was De Forest and others who, independently from each other, discovered in 1912 and 1913 that the triode could also amplify voice-frequency signals. Others also found that it could amplify high-frequency radio signals and that it could be used for radio transmission. These functions marked "the beginning of the modern age of electronics," says Chipman, "but De Forest played no large part in the development of that age." Nevertheless, in 1934, De Forest won the patent priority for the triode not only as an assemblage of parts but also for its applications. ${ }^{29}$

\section{Conclusion}

More could be said about the complicated human dimensions in the story of the beginning of electronics, including Shiers's observation that few inventions "have brought their inventors so much distress, disappointment and trouble as the oscillation valve brought Fleming," who never profited from the device financially, who saw it modified by De Forest before others used it to change the world, ${ }^{30}$ and who endured something of a long feud with De Forest. More important conclusions, however, might be illuminated via light the story may shed on the complicated human question of how world-changing innovations come into being. 
Comparison with one quite similar story might enhance any such illumination. While this paper neared completion, a narrative essay appeared in Nature ${ }^{31}$ by Charles H. Townes, who in 1964 shared the Nobel Prize in Physics for fundamental work in quantum electronics leading to the laser. Just as the present paper is about how Fleming's "very happy thought" while on a walk led to the beginning of electronics, the subheadline for Townes's essay says: "How a stroll in the park led to the beginning of quantum electronics." The beginning of electronics, the beginning of quantum electronics - whatever the risk of oversimplifying history by trying to discern recurring patterns, the two stories do have similarities. Both involve a Eureka moment stimulated by a technological desideratum. In Fleming's case the stimulus was the need for a rectifier. "The problem before me," Fleming said, "was to discover how to change this feeble electric oscillation into a feeble direct current ... ." In Townes's case the stimulus was the need "for ways of extending radar technology into the shorter wavelength region." For both stories' Eureka moments, the principal recalled years later the conversation he had had with himself. Fleming remembered recalling the one-way conductivity in an incandescent lamp, and remembered then saying to himself, "If that is the case we have here the exact implement required to rectify highfrequency oscillations." Townes remembered pondering the thermal limit on obtaining short wavelengths, and remembered then saying to himself, "But wait a minute! This assumes that the molecules are in thermal equilibrium. What if they weren't? A collection of excited molecules in complete non-equilibrium would have no such limit to their potential radiation intensity." And in both stories, the researcher, having made his Eureka connection and now needing to act on it, had access to the needed laboratory facilities, had adequate research assistance, and had the freedom to pursue the inspiration.

Of course, in at least one important way, the stories of the beginning of electronics and of the beginning of quantum electronics also diverge. Fleming's Eureka moment involved connectionmaking based on clear technological awareness, but Townes's Eureka moment involved connection-making based on deep scientific understanding. Notwithstanding the immediate technological desideratum, the context for Townes's breakthrough more closely resembled the purely scientific one in which Watson and Crick made their breakthrough than the mainly commercial-technological one in which Fleming made his. But then, like Watson and Crick, 
Townes worked a half-century later than Fleming, benefiting from technoscience's increased sophistication about connections between research and applications.

However, for all that science and technology changed from 1904 to the mid-1950s, and from the mid-1950s to the present, some features have obviously stayed constant. One constant is another similarity — an obvious and fundamental one - between the Fleming and Townes stories. Both involve the electron, the comparatively ancient member of the elementary-particle zoo that nevertheless still looks something like it did when discovered. As shown by Edison, Thomson, Fleming, the inventors of the transistor, Townes, and many others even now, the electron always has Eureka potential. Surely that is part of why we remember John Ambrose Fleming, who submitted a patent on November 16,1904, exactly a century before the commemorative conference session for which this paper was written. 


\section{Figure Captions}

1. John Ambrose Fleming (1849-1945), the British electrical engineer who invented the first vacuum tube. (Photograph courtesy Marconi, PLC)

2. Fleming's November 1904 note telling Guglielmo Marconi he had "found a method of rectifying electrical oscillations" but had not "mentioned this to anyone yet, as it may become very useful." (Fleming to Marconi, undated letter, circa Nov.30, 1904, Marconi, PLC Archives)

3. Fleming's design for the power plant and spark transmitter for Marconi's transatlantic wireless telegraph station (1901) in Cornwall, England. "A" is $20 \mathrm{~kW}$ generator connected to a series of spark-gaps and step-up transformers to a final tuned circuit antenna , $\mathrm{T}_{3}$. (British Patent Specification No.18,865; 1900).

4. An "Edison effect" experimental lamp that Fleming used in 1904 to demonstrate rectification. This was the prototype for Fleming's vacuum diode. The plate-like second electrode is clearly visible. (British Patent No. 24,850; November 16, 1904).

5. Early production version of a "Fleming valve." The second electrode surrounds the filament in this model. (Photograph courtesy, Marconi, PLC).

6. The first electronic circuit: Fleming's vacuum diode ("oscillation valve") as a detector in a wireless telegraph receiver. (Adapted from Ref. 7)

7. De Forest's vacuum triode, which he called the "audion." This tube contains three electrodes: the filament, a zig-zag wire "grid" and a plate-like anode. (Photograph courtesy www.leedeforest.org) 


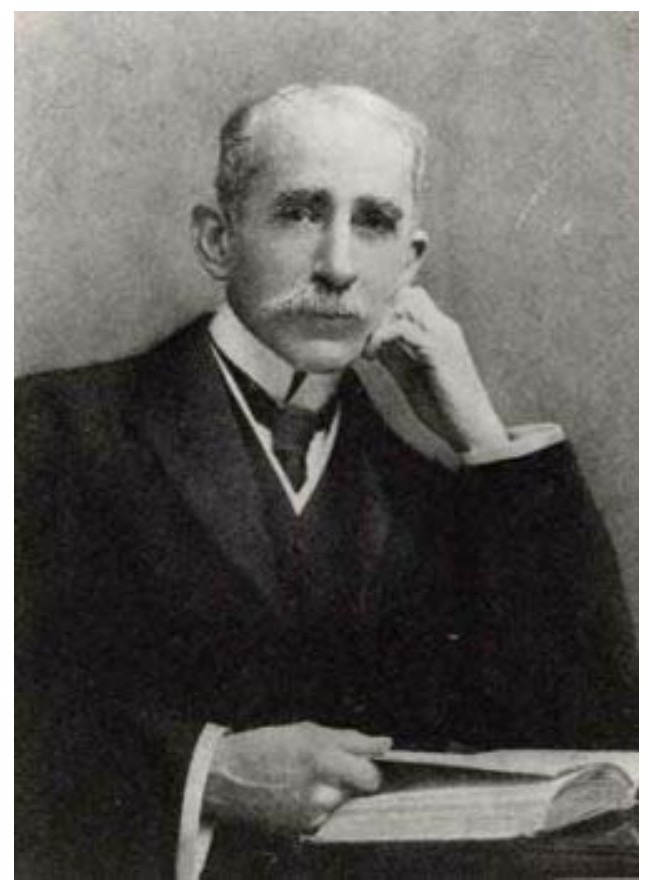

Figure 1 


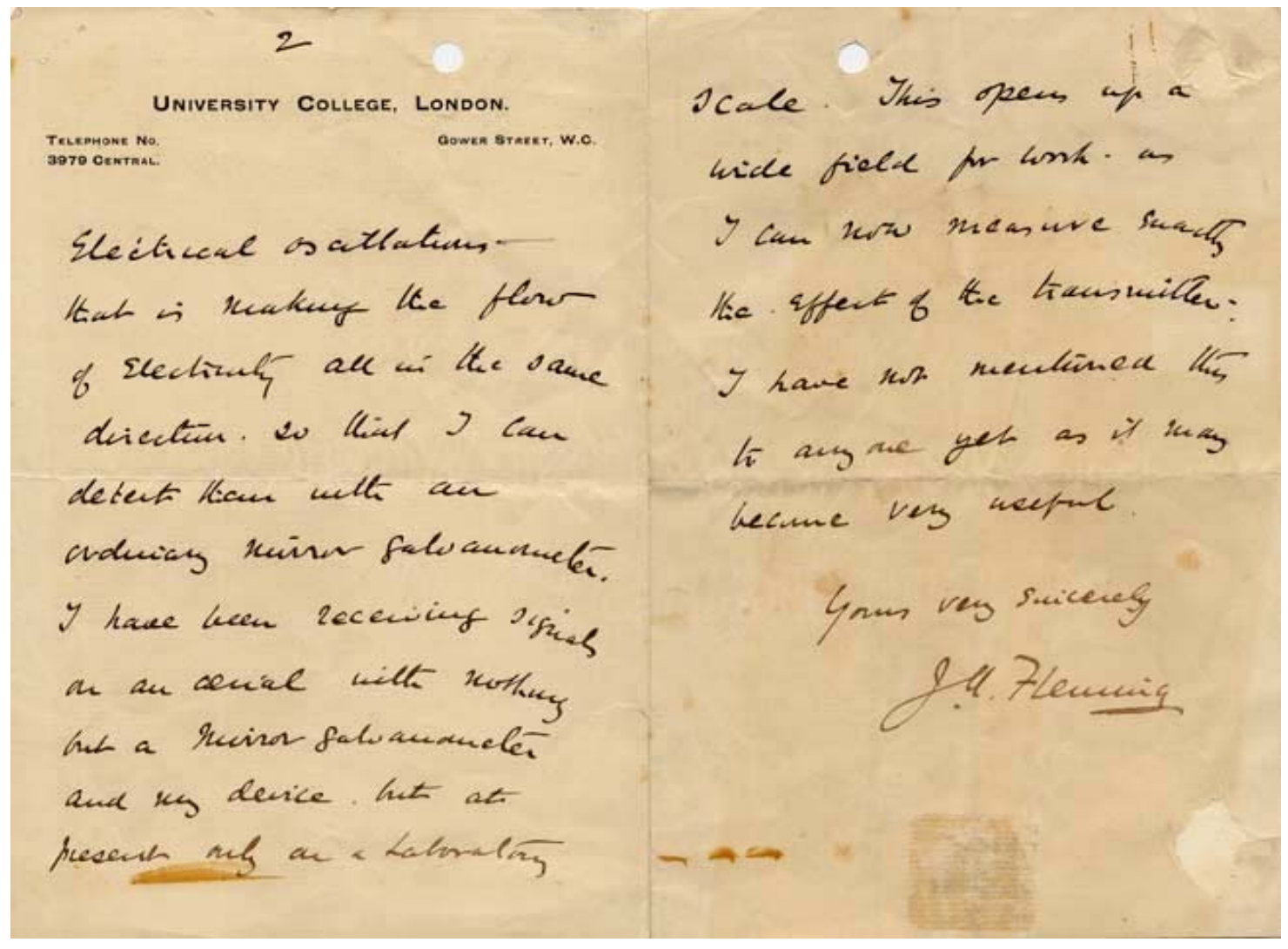

Figure 2 


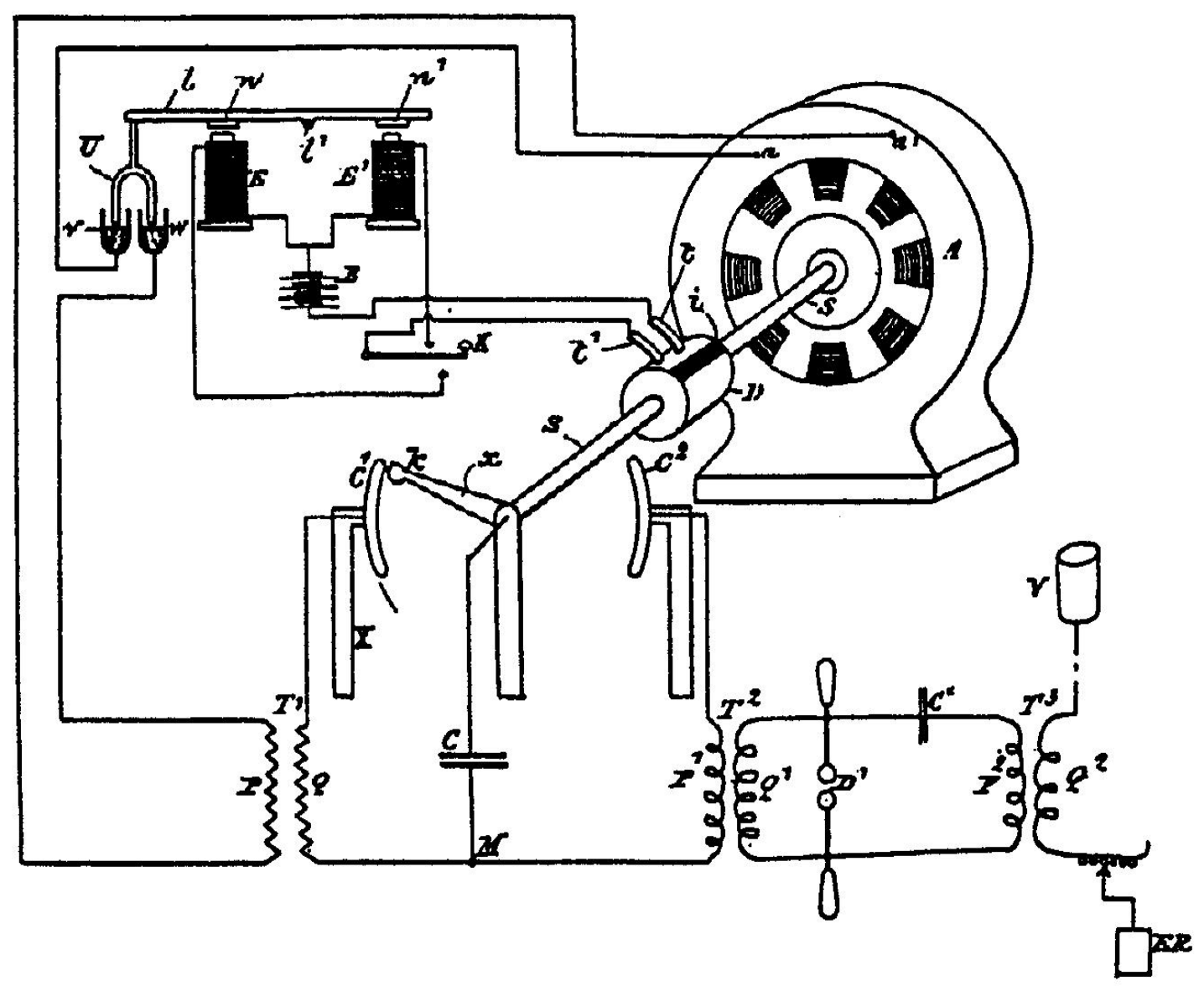

Figure 3 


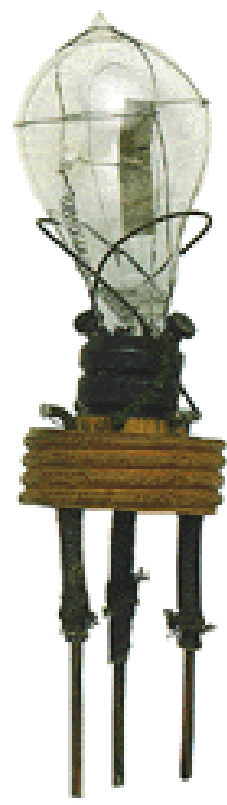

Figure 4 


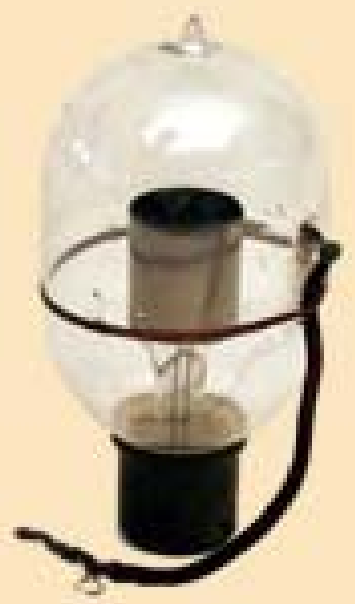

Figure 5 


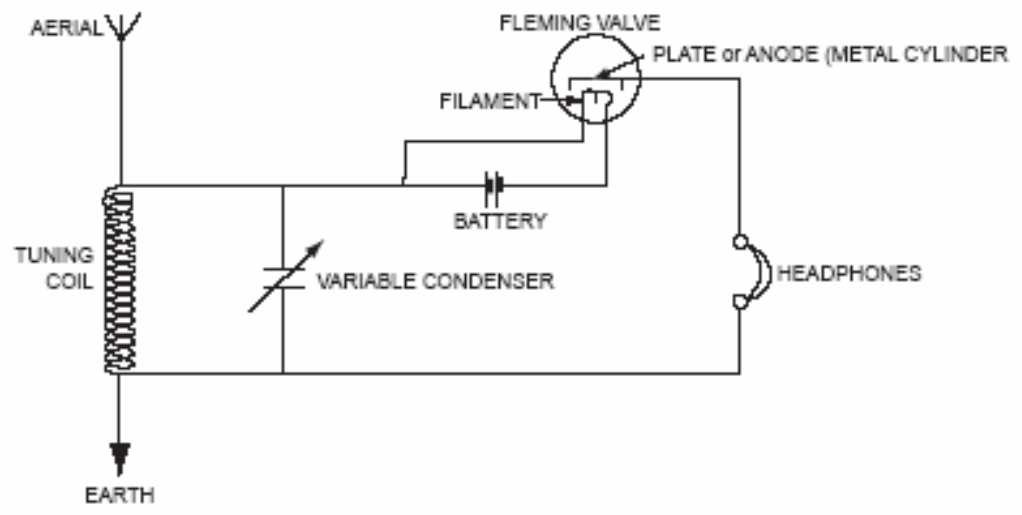

Figure 6 


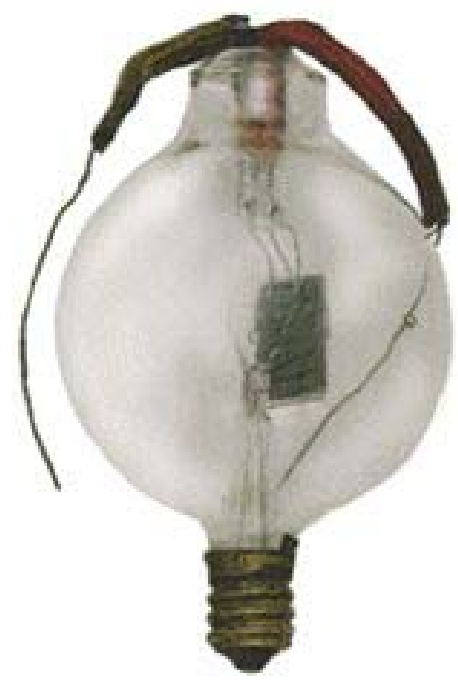

Figure 7 


\section{References (End Notes)}

${ }^{1}$ J. D. Watson and F. H. C. Crick, "Molecular structure of nucleic acids: a structure for deoxyribose nucleic acid," Nature 171, 737-738 (1953).

${ }^{2}$ U.K patent number 24850 . The U.S. patent—number 803684 , issued 7 Nov. 1905 -was called "Instrument for converting alternating electric currents into continuous currents."

${ }^{3}$ George Shiers, "The First Electron Tube," Scientific American, March 1969, 104-112, p. 104.

${ }^{4}$ Shiers, p. 111.

${ }^{5}$ P. A. Redhead, "The birth of electronics: thermionic emission and vacuum," J. Vac. Sci. Technol. A 16(3), May/June 1998, p. 1396.

${ }_{7}^{6} \mathrm{http} / / /$ www.r-type.org/static/fleming.htm

${ }^{7} \mathrm{http}: / / \mathrm{chem} . \mathrm{ch} . \mathrm{huji}$.ac.il/ eugeniik/history/fleming.htm

${ }^{8}$ J. T. MacGregor-Morris, The Inventor of the Valve: A Biography of Sir Ambrose

Fleming, London: The Television Society, 1954, p. 65.

${ }^{9}$ MacGregor-Morris, p. 73.

${ }^{10}$ Pauline Maier, Merritt Roe Smith, Alexander Keyssar, Daniel J. Kevles, Inventing America: A History of the United States (W. W. Norton, 2003), pp. xxi, 578, 690.

${ }^{11}$ Inventing America, pp. 691 and 578, respectively.

${ }^{12}$ Inventing America, pp. 577-579.

${ }^{13}$ Redhead, p. 1396.

${ }^{14}$ Shiers, p. 104.

${ }^{15}$ MacGregor-Morris, p. 69.

${ }^{16} \mathrm{http}: / /$ ieee.cincinnati.fuse.net/reiman/09_1989.html

${ }^{17}$ As quoted in Redhead, p. 1396, and p. 768 in J. B. Johnson, "Contribution of Thomas A. Edison to thermionics," American Journal of Physics, 28, \#9, December 1960, 763773.

${ }^{18}$ See Shiers p. 106 and Redhead p. 1396.

${ }^{19}$ U.S. patent 307031, issued 21 Oct. 1884.

${ }^{20}$ Shiers, p. 104; Johnson, p. 766.

${ }^{21}$ Shiers, pp. 104 and 109; Redhead, p. 1396; MacGregor-Morris, p. 67; Johnson, p. 772.

${ }^{22}$ MacGregor-Morris, pp. 74-77.

${ }^{23}$ Shiers, p. 111.

${ }^{24}$ Shiers, p. 111.

${ }^{25}$ Robert A. Chipman, "De Forest and the triode detector," Scientific American, March 1965, 93-100, p. 93.

${ }^{26}$ U.S. patent 879532, issued 18 Feb. 1908.

${ }_{28}^{27}$ Chipman, pp. 93 and $97-98$.

${ }^{28}$ Shiers, p. 109.

${ }^{29}$ Chipman, p. 100.

${ }^{30}$ Shiers, p. 111.

${ }^{31}$ Charles H. Townes, “Turning points: making waves," Nature 432, 153 (11 Nov. 2004). 